ISSN: 2415-038X (Print)

\title{
Kidney Disease for People Living with HIV in Sub-Saharan Africa; A Systematic Review
}

\author{
Brian Chanda Chiluba ${ }^{*}$ \\ ${ }^{1}$ School of Health Sciences, University of Zambia, Lusaka, Zambia.
}

*Corresponding author: brian.chiluba@unza.zm

\section{Abstract}

To cite: Chiluba BC,.Kidney Disease for People Living with HIV in Sub-Saharan Africa; A Systematic Review. JPRM 2021, 3(2): 7-13. doi: 10.21617/jprm2021.323

People living with HIV have been known to have a higher risk and threat of kidney disease. Globally, the prevalence of kidney disease for PLWH is postulated to be $6.4 \%$. This prevalence is different for many different parts of the world, with $7.9 \%$ in Africa, $7.1 \%$ in North America, $5.7 \%$ in Asia and 3.7\% in Europe. This systematic review set out to review and collect evidence from literature source and to provide a summary about factors influencing kidney disease for PLWH in Africa. We hypothesized that TDF containing ART is significantly associated with kidney disease. A systematic review and search of data was performed and all articles included were English articles from the following electronic databases: PubMed, Google Scholar and Embase. We carried out the selection of titles in three distinct phases: titles alone, abstracts, and then full text articles. 7 papers were included. While TDF was included in the ART regimens in all the studies, there was wide variation in ART combinations and concurrent medications and durations thereof. All studies except one included only adult patients of both men and women. Majority of the studies highlighted kidney disease and mostly these were hospital-based data. the findings establish a significant association between kidney disease and TDF use, but in terms of the clinical significance and weighting the risks against the benefits, we cannot discourage the continual use of the drug.

Keywords: Kidney disease, HIV, Systematic review, Sub-Saharan Africa 


\section{INTRODUCTION}

People living with HIV (PLWH) have been known to have a higher risk and threat of kidney disease. One of the constituents of a first line treatment is tenofovir disoproxil fumarate (TDF), which has nephrotoxic ability, characterized by proximal tubular cell injury. The administration of this drug for PLWH many times has been reported to cause acute kidney injury, continual kidney disorder or partial or complete Fanconi syndrome. Kidney impairments in PLWH are emerging as critical components of care and key in causing morbidity and mortality. In some studies, kidney diseases were reported to double the risk of death in HIV-infected patients [1].

Globally, the prevalence of kidney disease for PLWH is postulated to be $6.4 \%$. This prevalence is different for many different parts of the world, with $7.9 \%$ in Africa, $7.1 \%$ in North America, 5.7\% in Asia and 3.7\% in Europe [2]. The prevalence of HIV-associated kidney associated dysfunction seem to be generally lower with use of antiretroviral treatment (ART) but in the recent past specific forms of ART have been implicated for posing a higher risk of kidney disease for PLWH compared to the general population [3]. The commonly prescribed TDF is considered the most nephrotoxic molecule among currently used ART, especially over the short term. Beyond TDF, the protease inhibitors (PI), especially lopinavir (LPV) and ritonavir (RTV), are often reported as nephrotoxic [4].

Apart from traditional risk factors for kidney disease including diabetes, aging, and high blood pressure, the increased-risk for kidney disease for PLWH may be explained by HIV and ART-related factors as earlier explained [5]. Several studies have shown high viral load and low CD4 counts as risk factors for kidney disease or lower glomerular filtration rate (GFR) progression in PLWH [6].

In this era of ART has revolutionised the management of treatment for PLWH and ensuring that their life expectancy is as close as possible to that of the general population. Increasing the life expectancy for PLWH, however, poses risks for many HIV comorbidities. For example, the risk of cardiovascular disease (CVD) and kidney disease becomes the major problem for PLWH. For those that consequently develop kidney disease, the use of TDF has been known to be a critical component for the processes of the disease. At the same time in the recent past, the choice of tenofovir alafenamide (TAF) has arisen as it is documented to have a safer renal profile than TDF. TAF has a similar tolerability, safety, and effectiveness to
TDF and likely less damaging related to renal and bone density results within the remedy of naive and HIV patients who have been longer on treatment [7]. Given that TAF is documented as having higher viral suppression rates and better renal safety and bone density safety profiles, it has better clinical advantages over TDF and could be considered to replace TDF. Knowing the extent of renal safety of TDF in low resource settings would inform policy as to the need or priority to change patients to TAF. With the consideration that TAF has been reported as being better in terms of viral suppression effects and has a higher renal protection, it also has a more effective clinical preference over TDF. With the foregoing it has been under consideration as a drug of choice instead of TDF. In addition, TDF is known to be not readily available drug for renal protection in resource constrained settings, TAF may be considered a drug of choice.

For resource constrained settings like Africa, it is important when considering comorbidity data in PLWH to consider the role of age coupled with ART one is on. The aim of this review was to collect evidence from literature source and to provide a summary about factors influencing kidney disease for PLWH in Africa. We hypothesized that TDF containing ART is significantly associated with kidney disease METHODS AND MATERIALS

A systematic review and search of data was performed and all articles included were English articles from the following electronic databases: PubMed, Google Scholar and Embase. Some grey literature was also part of the search and original studies reports were considered including, unpublished thesis and dissertations from Thesis Global database. We carried out the selection of titles in three distinct phases: titles alone, abstracts, and then full text articles. 7 papers were included. Articles written in English with full abstract were included. In order to assess the methodological quality of the articles to be included in the study a CASP tool was used.

\section{Search Strategy}

Search 1: A simultaneous search of electronic databases, MEDLINE, PubMed, Google Scholar, was conducted to locate articles relating to HAART, Acute kidney Function and HIV published between January 2010 and October 2019. The search was conducted using the terms "kidney AND HIV or Risk of acute kidney in HIV," Search 1 resulted in 431 articles, after electronic removal of duplicates, search 2 resulted in 88 . The searches combined resulted in 88 publications in total with full texts. See the 
proforma for quantitative studies attached (appendix II).

\section{Identification of intervention and dissemination studies}

1. Exclusion Criteria: Articles were excluded if: (a) the study sample was not predominantly Indigenous Africans ( $n=377)$; (b) HIV on ART or TDF implications for PLWH was not the primary focus of the study or a primary outcome measure (c) publications were duplicates or not journal articles. A total of 81 articles were excluded, leaving 7 articles.

\section{RESULTS}

A total of 88 articles from three already mentioned database were retrieved from both main and additional sources. Of the 88 retrieved articles, a total of 81 were removed based on the exclusion criteria of the review as shown in (Fig. 1). With full articles excluded because they could not meet their inclusion criterial, the final articles that qualified and be included for the study were 7 papers.

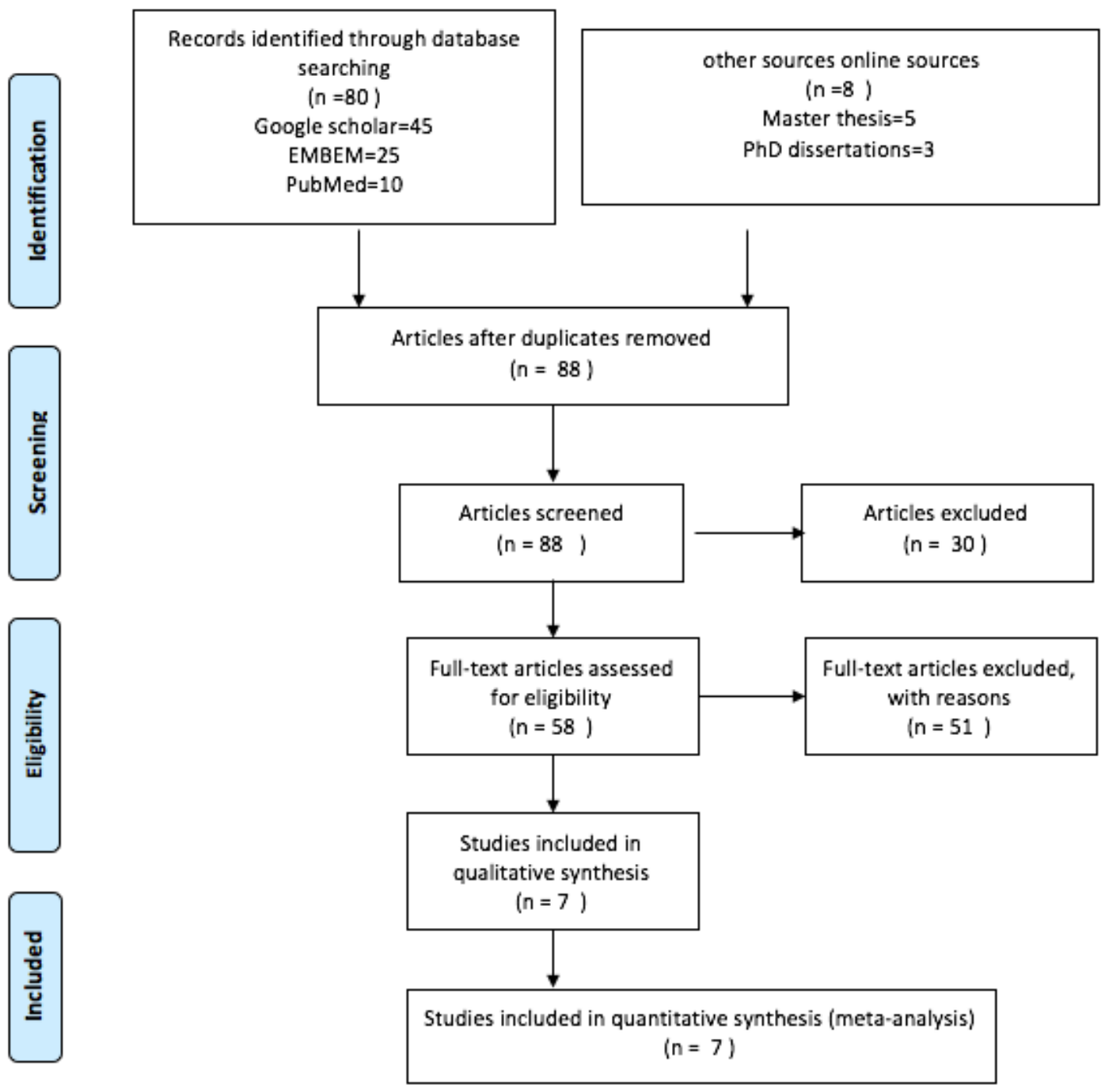

Figure 1: PRISMA Article search results 


\section{Characteristic of reviewed study participants}

For all the studies included in this review, a total sample of 1,142 PLWH was observed with the mean age range of 28.2 to 42.4 years. The regional distribution of the studies was that, three studies were done in South-Africa, and one in Namibia, two in Zambia, and one in Nigeria. (Table 1). From the studies reviewed most of the PLWH took tenofovir-containing ART up to 9 years.

Table 1: Profile of articles Included for Review

\begin{tabular}{|c|c|c|c|c|c|c|c|}
\hline Author: & Setting/Regi & Age group of & Design & $\begin{array}{r}\text { Sample } \\
\text { containing }\end{array}$ & Treatment & $\begin{array}{l}\text { ART } \\
\text { Duration }\end{array}$ & follow up time \\
\hline Mulubwa: & South Africa: & Adult women & CS & $30(30)$ & $300 \mathrm{mg}$ TDF & - & Cross sectional \\
\hline Tewogbade: & Nigeria:WA & Adults & PC & 55 (19) & $T D F+3 T C+E F V$ & - & 12 months \\
\hline Gajee: 2016 & South Africa & Adults 20-40 & $\mathrm{RC}$ & $66(66)$ & TDF containing & 12 month & 12 months \\
\hline Kalemeera: & Namibia & Adults & $\mathrm{RC}$ & $71(71)$ & Second line TDF & - & Cross sectional \\
\hline Seedat: & South Africa & $\geq 15$ years & PC & 175 & 93 TDF exposed, & - & Duration of \\
\hline Banda: & Zambia & Adults & CS & 300 & TDF containing & Not & Cross sectional \\
\hline Wantakisha: & Zambia: SA & Adults $\geq 15$ years & CS & 445 & TDF containing & 18months & Cross-sectional \\
\hline
\end{tabular}

*Designs: $R C$ retrospective cohort, $P C$ prospective cohort, $C S$ cross sectional, $R C T$ randomized control trial,

Of the 7 studies included in this analysis, 3 were cohort studies of which two were retrospective cohort and the other one was prospective cohort studies. Four (4) studies were cross-sectional. The period of intake of tenofovir varied from 0 to 2 years. While TDF was included in the ART regimens in all the studies, there was wide variation in ART combinations and concurrent medications and durations thereof. All studies except one included only adult patients of both men and women and only the study by Mulubwa included adult women. Majority of the studies highlighted kidney disease and mostly these were hospital-based data. These studies commonly focused on the risk of kidney disease for people with HIV and are on second line treatment. None of the population-based studies reported incidence of kidney disease. 
Table 3: Summary of findings for the selected study

\begin{tabular}{|c|c|c|c|}
\hline $\begin{array}{l}\text { Author: } \\
\text { year }\end{array}$ & Findings & $\begin{array}{l}\text { TDF relationship conclusion } \\
\text { by author }\end{array}$ & $\begin{array}{l}\text { clinical } \\
\text { significane } \\
\mathrm{e}\end{array}$ \\
\hline $\begin{array}{l}\text { Banda: } \\
2010\end{array}$ & $\begin{array}{l}\text { TDF was not associated with RD (1.03: } 0.45-2.37 \text {, } \\
95 \% \mathrm{CI})\end{array}$ & TDF not associated with RD & N/A \\
\hline $\begin{array}{l}\text { Eritzsche: } \\
2017\end{array}$ & $\begin{array}{l}\text { PuThe proportion of pts with an } \mathrm{gGER}<60 \mathrm{ml} / \mathrm{min} \\
\text { was significantly higher among treatment naive pts } \\
\text { than among those on TDF treatment }(40.4 \% \mathrm{vs} \\
24.4 \% ; \mathrm{p}=0.041) \text {. }\end{array}$ & $\begin{array}{l}\text { TDF appears to be safe and } \\
\text { does not appear to be a } \\
\text { significant cause of renal } \\
\text { impairment }\end{array}$ & N/A \\
\hline Gajee: 2016 & $\begin{array}{l}\text { The } \mathrm{CrCl} \text { in the younger age group ( } \geq 20 \text { to } \\
<30 \text { years) exhibited an increase in } \mathrm{CrCl} \text { at } \\
12 \text { months post-TDF commencement. The older } \\
\text { age group ( } \geq 30 \text { to } \leq 40 \text { years) displayed a } \\
\text { decrease in } \mathrm{CrCl} \text { at } 12 \text { months post-TDF } \\
\text { commencement for females and males }\end{array}$ & Safe & $\begin{array}{l}\text { Age and } \\
\text { gender } \\
\text { influence } \\
\text { kidney } \\
\text { function }\end{array}$ \\
\hline $\begin{array}{l}\text { Mulubwa: } \\
2016\end{array}$ & $\begin{array}{l}\text { positive correlation was found between TFV } \\
\text { plasma concentration and albuminuria } \\
\text { (unadjusted } r=0.606 ; p=0.001 \text {. TFV } \\
\text { concentration was independently associated with } \\
\text { increased albuminuria }\end{array}$ & $\begin{array}{l}\text { Plasma TFV concentration is } \\
\text { independently associated with } \\
\text { increased albuminuria in HIV- } \\
\text { infected women within this } \\
\text { pilot investigation. There was } \\
\text { an increase in eGFR and } \mathrm{CrCl} \text { in } \\
\text { the HIV-infected women from } \\
\text { baseline }\end{array}$ & Moderate \\
\hline Seedat: & $\begin{array}{l}61 \% \text { of TDF grp had AKI on admission vs } 43 \% \text {. } \\
\text { Discharge median } \mathrm{SCr} \text { was higher in the TDF group } \\
\text { and fewer in the TDF group recovered renal } \\
\text { function after } 3 \text { months }\end{array}$ & $\begin{array}{l}\text { TDF has an added nephrotoxic } \\
\text { effect in patients with AKI } \\
\text { causing: a more rapid } \\
\text { worsening of renal function; a } \\
\text { higher proportion with } \\
\text { proteinuria and acidosis; and } \\
\text { delayed renal recovery }\end{array}$ & $\begin{array}{l}\text { Notably } \\
\text { high }\end{array}$ \\
\hline $\begin{array}{l}\text { Wantakisha; } \\
2017\end{array}$ & $\begin{array}{l}\text { Point prevalence of renal dysfunction among HIV- } \\
\text { positive adults exposed to TDF was } 18.6 \% \text {. } \\
\text { Patients with a CD } 4+\text { cell count }>350 \text { cells/uL had } \\
\text { decreased odds of developing renal dysfunction }\end{array}$ & $\begin{array}{l}\text { Renal dysfunction was } \\
\text { concentrated in older patients } \\
\text { with low CD } 4 \text { + cell count. }\end{array}$ & $\begin{array}{l}\text { High } \\
\text { burden }\end{array}$ \\
\hline $\begin{array}{l}\text { Tewogbade: } \\
2010\end{array}$ & $\begin{array}{l}\text { The plasma creatinine also improved significantly } \\
\text { from the pre-treatment value of } 131.1 \mu \mathrm{\mu mgl} / \mathrm{L} \text { to } \\
93.4 \mu \mathrm{mol} / \mathrm{L} \text { at } 9 \text { months but two patients values } \\
\text { increased from } 346 \text { and } 44 \mu \mathrm{\mu mgl} / \mathrm{L} \text { to } 707 \text { and } \\
563 \mu \mathrm{mol} / \mathrm{L}\end{array}$ & Desirable safety & N/A \\
\hline
\end{tabular}




\section{DISCUSSION}

This systematic review of the available studies showed that kidney disease is becoming very prevalent and burdensome for PLWH across sub-Saharan Africa with risk factors that include both communicable and non-communicable diseases. It should be realized thought that due to different study design, measurements, sample size and sampling methods is a major limitation for comparison. In most of these studies, they also lacked consistence in the dependent variable being measured [8].

There is an indication of conflicting findings from the different studies for this review as summarized in (Table 2). The conflict borders on the role of TDF in causing renal dysfunction. During follow up terms of up to 2 years, $30 \%$ of the studies suggest overall safety of tenofovir while the other $70 \%$ have indicated report differing evidence on levels of renal toxicity of TDF. Fifteen studies reported that there is neither statistical nor clinical association of TDF with renal function decline in HIV-positive patients [9]. On the other hand, 6 studies reported an association with seven of these reporting the association as significant (Table 2).

Two studies that were done in Southern Africa [10]. One of the studies could not establish the association of TDF to renal disease in PLWH. In this review only 5 studies reported the effect of other factors apart from the influence of ART [11]. However, Cournil et al. Advocate that an interaction among Tenofovir and Ritonavir can be answerable for preliminary decrease in eGFR found while a affected person's initiates on a ritonavir boosted TDF routine. Some authors, however, support the notion that TDF toxicity is made worse when combined with other regimens [12]. This is even more critical in ageing HIV populations with increased lifespans.

Some of the reasons that have been advanced for a higher kidney disease in Africa is the idea of having to wait to initiate someone of ART. Most of the PLWH tend to be initiated on ART when HIV had advanced and most changes in body profile have already taken place. This is even made clear because PLWH in Africa tend to have lower CD4 cell count compared to other parts of the world [13]. In other parts of the world, the practice is that all PLWH are commenced on ART immediately after diagnosis irrespective of CD4 cell count. However, the practice seems to be gaining momentum in sub-Saharan Africa as of 2016 most of the SSA countries have adopted the practice of initiating PLWH on ART immediately without waiting. Even though this is so, the effects of this adoption on kidney disease prevalence for PLWH will only become evident in many years to come [14].

This study found that TDF exposure places HIV positive patients at a higher risk for kidney disease as highlighted in all the seven studies. This is an indication of the disease distribution in the population affecting the therapeutic measures currently available. The high incidences can further be explained by the long duration of the disease because renal dysfunction is being missed at follow up. Considering that these patients are on these drugs for such a long duration, screening at every follow up visit could be intensified [12]. This was further supported with evidence that those patients exposed to TDF were 2.7 more likely to develop renal dysfunction with 2.9 odds than those not exposed to it. Other studies have found renal dysfunction among those exposed to TDF and had a baseline CD4 cell count 0.05 ) on both univariate and multivariate analysis. It however does indicate that renal disease is more likely to occur in the exposed group. Further, the prevalence of acute renal dysfunction in this study was found to be $28.5 \%$ which agrees with similar studies done ranging from $27.5 \%$ to $42 \%$ [ 


\section{CONCLUSION}

This review highlighted kidney disease among PLWH in Africa, the finings establish a significant association between kidney disease and TDF use, but in terms of the clinical significance and weighting the risks against the benefits, we cannot discourage the continual use of the drug. However, considering the confounding effects of other variables like advance in age, previous kidney problem, PLWH who take TDF maybe at even a higher risk than what has been imagined. Base on this, there is need for future research to establish the interdependence of other factors leading to renal disease.

Contributors Conceptualization and write-up: Brian Chanda Chiluba.

Competing interests There were no competing interests from all authors in this study.

\section{REFERENCES}

1. Habib MA, Black K, Soofi SB, Hussain I, Bhatti Z, AIDSinfo. Guidelines for the use of Antiretroviral Agents in HIV-1 infected Adults and Adolescents 2016 16th November 2016 https://aidsinfo.nih.gov/contentfiles/lvguidelines/AA_R ecommendations.pdf.

2. Banda J, Mweemba A, Siziya S, Mweene M, Andrews B, Lakhi S. Prevalence and factors associated with renal dysfunction in HIV positive and negative adults at the University Teaching Hospital, Lusaka. Med J Zambia. 2010, 37(3):136-142

3. Coca S, Perazella MA. Rapid communication: acute renal failure associated with tenofovir: evidence of drug-induced nephrotoxicity. Am J Med Sci. 2002, 324(6):342.

4. Cooper RD, Wiebe N, Smith N, Keiser P, Naicker S, Tonelli M. Systematic review and meta-analysis: renal safety of tenofovir disoproxil fumarate in HIV-infected patients. Clin Infect Dis. 2010, 51(5):496-505.

5. Fernandez-Fernandez B, Montoya-Ferrer A, Sanz AB, Sanchez-Niño MD, Izquierdo MC, Poveda J, et al. Tenofovir nephrotoxicity: 2011 update. AIDS Res Treat. 354908-11.

6. Kamkuemah M, Kaplan R, Bekker LG, Little F, Myer L. Renal impairment in HIV-infected patients initiating tenofovir-containing antiretroviral therapy regimens in a Primary Healthcare Setting in South Africa. Trop Med Int Health. 2015, 20(4):518-526. doi: 10.1111/tmi.12446.

7. Moher D, Liberati A, Tetzlaff J, Altman DG, The PG. Preferred reporting items for systematic reviews and meta-analyses: the PRISMA statement. PLoS Med. 2009, 6(7):e1000097.
8. Mulenga L, Musonda $\mathrm{P}$, Mwango A, Vinikoor MJ, Davies MA, Mweemba A, et al. Effect of baseline renal function on tenofovir-containing antiretroviral therapy outcomes in Zambia. Clin Infect Dis. 2014, 58(10):1473-1480. doi: 10.1093/cid/ciu117

9. Mulubwa $M$, Rheeders $M$, Fourie $C$, Viljoen $M$. Associations between plasma tenofovir concentration and renal function markers in HIV-infected women. S Afr J HIV Med. 2016, 17(1):a458. doi: 10.4102/sajhivmed.v17i1.458.

10. Nelson MR, Katlama C, Montaner JS, Cooper DA, Gazzard B, Clotet B, et al. The safety of tenofovir disoproxil fumarate for the treatment of HIV infection in adults: the first 4 years. AIDS (London, England). 2007, 21:1273-81.

11. Sax PE, Gallant JE, Klotman PE. Renal safety of tenofovir disoproxil fumarate. AIDS Reader. 2007, 17(2):90-2.

12. Seedat F, Martinson N, Motlhaoleng K, Abraham P, Mancama D, Naicker S, et al. Acute kidney injury, risk factors, and prognosis in hospitalized HIV-infected adults in South Africa, compared by tenofovir exposure. AIDS Res Hum Retroviruses. 2017, 33(1):33-40. doi: 10.1089/aid.2016.0098

13. Tewogbade AA. Effects of highly active antiretroviral therapy haart on the renal function of HIV/AIDS patients at the university of Ilorin Teaching Hospital, Ilorin. Faculty of Pathology: Nigeria; 2010

14. Wang $H, L u X$, Yang $X, X u N$. The efficacy and safety of tenofovir alafenamide versus tenofovir disoproxil fumarate in antiretroviral regimens for HIV-1 therapy: meta-analysis. Medicine. 2016, 95(41): e5146.

15. Wantakisha E, Chongwe G, Munkombwe D, Michelo C. Renal dysfunction among HIV-infected patients on tenofovir-based antiretroviral therapy at Ronald Ross Hospital in Zambia. J AIDS Clin Res. 2017, 8(1):651 